\title{
Comparative study between anterior and posterior scoring in otoplasty for bat ear
}

\section{Original Article}

\author{
Abdelazim, Mohamed Hussein, Ismaeil, wael fawzy \\ Department of Otorhinolaryngology, Al-Azhar Faculty of Medicine New Damietta; Egypt.
}

\begin{abstract}
This study is meant to compare between anterior and posterior scoring techniques for the correction of prominent ear primarily in terms of cosmesis and patients' satisfaction. We included 50 patients who were randomly assigned to anterior scoring (AS; 25 subjects with a total of 45 ears) or posterior score (PS; 25 subjects with a total of 47 ears). All patients were subjected to full history taking, general \& local examinations and laboratory investigations. We analyzed the age, sex, surgical technique, the need for a second operation, type of anesthetics, additional procedures, follow-up, complications, and results. Both groups were comparable as regard patient characteristics, laterality of prominent ear, intra-operative and follow up measurements and complications. However, posterior scoring results in a high satisfaction rate with low morbidity. It was shown to be safe (low complication rate), simple and reliable intervention. Thus, we advocate posterior scoring during correction of prominent ears deformity.
\end{abstract}

Key Words: Bat ear, otoplasty, prominent ear, scoring

Received: 9 April 2018, Accepted: 22 June 2018

Corresponding Author: Abdelazim, Mohamed Hussein, Department of Otorhinolaryngology, Al-Azhar Faculty of Medicine New Damietta; Egypt., Tel.: +20473860840, E-mail: mohammedabdelazeem35@yahoo.com

ISSN: 2090-0740, June 2018, Vol.19, No.2

\section{INTRODUCTION}

Prominent ear is the most common deformity encountered in the ear. The incidence of prominent ear is about $5 \%$ of normal deliveries and it usually presents bilaterally ${ }^{[1]}$. Prominent ear is inherited as an autosomaldominant with different degrees of penetration. It usually occurs during fetal development at approximately the tenth week of intrauterine life. The abnormal appearance of prominent ear usually presents early in life, as $85 \%$ of auricular growth is completed by the age three years ${ }^{[2,3]}$.

Prominent ear (Protruding or lop ear) is characterized by an increase in the cephalo-auricular angle, which occurs due to an immature antihelical fold; an excessive conchal cartilage; or abnormal attachment of the auricle to the side of the head, alone or in combination ${ }^{[4]}$.

At the start of the school, patients with prominent ear are usually exposed to psychological distress. Thus it is advisable to correct the deformity before school attendance (at 4-6 years $)^{[5,6]}$.

The helical rim usually $17-21 \mathrm{~mm}$ distance from mastoid bone ${ }^{[7]}$ and the auriculo-mastoid angle is about 20-30 degrees ${ }^{[8]}$. These measurements are considered normal for the ear position, and any deviation beyond these criteria is considered prominent ears ${ }^{[3]}$.

From the anatomical point of view, a prominent ear lacks the antihelix fold or the big conchal bowl, or a combination of both abnormalities. The detection of the degree of involvement of these components usually guide the successful surgical intervention ${ }^{[7,9]}$. The first successful surgery for prominent ear surgery dates back to 1845 and was performed by Dieffenbach. Subsequently, more than 200 different techniques have been introduced. This high number of interventions indicates that, there is no single successful procedure yet to satisfy all surgeons. All techniques are usually based on two main categories. Suturing and sculpting are the most commonly performed procedures ${ }^{[10,11,12]}$. Suture procedures are usually used to permanently suture different auricular parts to create a helical fold or fixate the auricle to the mastoid bone. The sculpting technique performed by making incisions and excisions, followed by scoring. The combination of both suturing and sculpting is usually preferred by many surgeons ${ }^{[13,8]}$.

The present study was designed to compare between anterior and posterior scoring in the treatment of prominent ear.

\section{METHODOLOGY:}

Before the commencement of this study, the Institutional Review Board has approved the protocol of the investigation and the investigators have obtained written informed consent from each participant or each participant's guardian.

We included 50 patients who presented with prominent ear during the study period (extending between June 
2014 till June 2016). They were recruited from Al-Azhar University Hospital (Otorhinolaryngology Department/ Plastic Surgery Department). They were randomly assigned to anterior scoring (AS) or posterior scoring (PS). Randomization was done by closed envelope method, where group A was assigned to number 1 and group B was assigned to number 2 , and each of generated numbers was contained in an envelope, closed and opened just before surgery by a nurse not incorporated in the study. The AS group included 25 subjects with a total of 45 ears (5 unilateral and 20 bilateral); and the PS group included 25 subjects with a total of 47 ears ( 3 unilateral and 22 bilateral). Each ear was considered as a separate variable.

All patients were subjected to: 1) full history taking, general and local examinations for the shape of the auricle, anti-helical fold, conchal cartilage, any scar, any other anomalies and ear discharge; palpation for tenderness and any mass; then measuring of cephaloauricular distance. Furthermore, all patients were investigated for fitness for operation such as complete blood count, international normalized ratio, blood sugar, liver and kidney functions. The follow up for each patient included: 1) Photography (frontal, back, right and left lateral views) preoperative and postoperative (one week, one month, six months and one year); and 2) Measuring of cephaloauricular distance preoperative and postoperative (one week, one month, six months and one year). The position of the ear was measured from the lateral most aspect of the helical rim and lobule to the mastoid skin at the following specific locations: 1) superior-most aspect of the helix; 2) halfway between the superior-most aspect and the cauda helix; 3) cauda helix; and 4) lobule. All measurements were performed by using a surgical caliper postoperatively. In addition, we analyzed the age, sex, surgical technique, the need for a second operation, type of anesthetics, additional procedures, follow-up (as previously described), complications, and results.

2.1. Exclusion criteria: Included the following: 1) Any medical condition that interferes with the operation such as: blood disease; and 2) Associated anomalies (as hemangima - canal atresia).

2.2. Anterior scoring technique: Surgery was performed under general anesthesia with the patient in the supine position and the ear to be operated upon facing upward. The auricular and periauricular region were prepped and draped. The new antihelical fold location was determined by pressing the scaphoid fossa to the mastoid region. The site of new antihelical fold is marked anteriorly by methylene blue dye (a 25 -gauge needles are inserted from the anterior marks to exit from the posterior side. The skin was infiltrated with a solution of $1 \%$ xylocaine with epinephrine $1: 200000$. An ellipse of skin from the posterior aspect of the auricle was removed .The skin was dissected off the posterior aspect through the incision. Sharp scissors were used to open a tract to scrape and score the cartilage. Access to the front of the ear was done using the incision behind the ear making tunneling through which an oto-rasp was used to score the antihelix anteriorly (Fig. 1).

The postauricular incision was closed using interrupted Vicryl 3-0 sutures. Finally, the anterior side of the ears' grooves was filled by Vaseline-saturated cotton. The posterior side was covered with antibioticsaturated gauze and the head was dressed with an elastic bandage. Before leaving the intraoperative room a single dose of selected antibiotic was administered and the patient is continued on oral antibiotics for a week.

2.3. Posterior scoring technique: Surgery was performed under general anesthesia with the patient in the supine position and the ear to be operated upon facing upward. The skin was infiltrated with a solutio $\mathrm{n}$ of $1 \%$ xylocaine with epinephrine 1: 200 000. An ellipse of skin from the posterior aspect of the auricle was removed .The skin was dissected off the posterior aspect through the incision. Posterior scoring of the perichondrium and cartilage was performed using a no. 15 blade (Fig.2).

The auricle was bent backwards and stabilized with three permanent prolene Mustar de sutures, creating a new antihelical fold. The auricular perichondrium was then sutured to the mastoid periosteum using prolene Furnas sutures. The postauricular incision was closed using interrupted Vicryl 3-0 sutures. Finally, the anterior side of the ears' grooves was filled by Vaseline-saturated cotton. The posterior side was covered with antibioticsaturated gauze and the head was dressed with an elastic bandage. Before leaving the intraoperative room a single dose of selected antibiotic was administered and the patient is continued on oral antibiotics for a week.

2.4. Statistical analysis of data: The collected data were organized, tabulated and statistically analyzed using statistical package for social science (SPSS), version 18 (SPSS Inc. Chicago, USA), running on IBM compatible computer. Numerical data (quantitative) were represented as mean and standard deviation; while categorical data (Qualitative) were represented as relative frequency and percent distribution. For comparison between groups, student samples $(\mathrm{t})$ test or Chi square (X2) was used for quantitative and qualitative data respectively. A P-value $<0.05$ was considered significant for all variables.

\section{RESULTS}

The In the present work, age ranged from 4 to 25 years with a mean of $9.86 \pm 5.27$ years and there was no significant difference between anterior and posterior scoring groups (9.52 \pm 5.06 ; vs $9.84 \pm 5.56$ years respectively). In addition, there was no significant difference between AS and PS groups as regard to sex distribution (males represnted $72 \%$ and $60.0 \%$ respectivley). Eight patients had unilateral prominent ear representing $16 \%$ of all studied patients and 
42 patients $(84.0 \%)$ had bilateral prominent ear and there was no signficant differnce between AS and PS groups (bilateral prominent ear were observed in $80.0 \%$ and $88.0 \%$ of AS and PS groups respectivley). Finally, 44 promienent ears $(47.8 \%)$ were on right side and 48 ears $(52.2 \%)$ were on the left side and there was no signficant differnce between AS and PS groups (right side was reported in $44.4 \%$ and $51.1 \%$ of AS and PS groups respectivley) (table I).

In addition, there was no statistically significant difference between AS and PS groups as regard to measurements at different points (superior helix, point b, cauda helix and lobule). Also, there was statistically nonsignificant difference at the end of follow up period when compared to values at one week postoperatively (table II).
As regard complications, there was no statistically significant difference between AS and PS groups as regard to hematoma (reported in one case in AS group only), tissue necrosis (reported in none in each group), local infection (reported in one case in AS group only), local hypothesia (reported in one case in PS group), superficial ulceration (reported in none of each group), suture extrusion (reported in 2 cases in AS group), suture granuloma (reported in 2 cases in AS group), hypertrophic scarring (reported in 2 cases in AS group) and residual asymmetry (3 cases in AS group and 1 in PS group). The total complication rate in AS group was $11.1 \%$ compared to $2.2 \%$ in PS group. The satisfaction rate was significantly higher in PS group when compared to AS group ( $97.9 \%$ vs $86.7 \%$ respectively) (table III)

Table (I): Patient characteristics in studied populations

\begin{tabular}{|c|c|c|c|c|c|c|}
\hline \multicolumn{2}{|c|}{ Variable } & AS group & PS group & Total & Test & $\mathrm{P}$ value \\
\hline \multicolumn{2}{|c|}{$\begin{array}{l}\text { Age (mean } \pm \mathrm{SD} ; \\
\text { range) }\end{array}$} & $\begin{array}{c}9.84 \pm 5.56 \\
4-25\end{array}$ & $\begin{array}{l}9.52 \pm 5.06 \\
5-25\end{array}$ & $\begin{array}{c}9.86 \pm 5.27 \\
\quad 4-25\end{array}$ & 0.21 & 0.41 (ns) \\
\hline \multirow[t]{2}{*}{$\operatorname{Sex}(n, \%)$} & Male & $18(72.0 \%)$ & $15(60.0 \%)$ & $33(66.0 \%)$ & 0.80 & 0.73 (ns) \\
\hline & Female & $7(28.0 \%)$ & $10(40.0 \%)$ & $17(34.0 \%)$ & & \\
\hline \multirow[t]{2}{*}{ Laterality } & Unilateral & $5(20.0 \%)$ & $3(12.0 \%)$ & $8(16.0 \%)$ & 0.59 & 0.44 (ns) \\
\hline & Bilateral & $20(80.0 \%)$ & $22(88.0 \%)$ & $42(84.0 \%)$ & & \\
\hline \multirow[t]{2}{*}{ Side } & Right & $20(44.4 \%)$ & $24(51.1 \%)$ & $44(47.8 \%)$ & 0.40 & $0.52(\mathrm{~ns})$ \\
\hline & Left & $25(55.6 \%)$ & $23(48.9 \%)$ & $48(52.2 \%)$ & & \\
\hline
\end{tabular}

Table (II): Measurements over time in studied populations

\begin{tabular}{|c|c|c|c|c|c|c|c|}
\hline & & \multicolumn{2}{|c|}{ AS } & \multicolumn{2}{|c|}{ PS } & \multirow[t]{2}{*}{ Test } & \multirow[t]{2}{*}{$P$ value } \\
\hline & & Mean & S. D & Mean & S. D & & \\
\hline \multirow{5}{*}{$\begin{array}{l}\text { Superior helix } \\
\text { (A point) }\end{array}$} & Intraoperative & 10.86 & 0.014 & 10.86 & 0.015 & 0.21 & $0.82(\mathrm{~ns})$ \\
\hline & One week PO & 10.96 & 0.061 & 10.99 & 0.061 & 1.66 & $0.09(\mathrm{~ns})$ \\
\hline & One month PO & 11.29 & 0.028 & 11.30 & 0.011 & 1.51 & $0.13(\mathrm{~ns})$ \\
\hline & 6 months PO & 11.36 & 0.017 & 11.36 & 0.019 & 0.91 & $0.36(\mathrm{~ns})$ \\
\hline & One year PO & 11.39 & 0.012 & 11.39 & 0.017 & 0.57 & $0.56(\mathrm{~ns})$ \\
\hline \multirow{5}{*}{$\begin{array}{l}\text { Midpoint } \\
\text { between } \\
\text { A and C } \\
\text { (B point) }\end{array}$} & Intraoperative & 13.45 & 0.014 & 13.44 & 0.014 & 0.80 & $0.42(\mathrm{~ns})$ \\
\hline & One week PO & 13.47 & 0.010 & 13.47 & 0.011 & 1.13 & $0.26(\mathrm{~ns})$ \\
\hline & One month PO & 13.50 & 0.011 & 13.50 & 0.010 & 0.63 & $0.52(\mathrm{~ns})$ \\
\hline & 6 months PO & 13.60 & 0.007 & 13.60 & 0.006 & 0.15 & $0.87(\mathrm{~ns})$ \\
\hline & One year PO & 13.65 & 0.008 & 13.64 & 0.008 & 0.50 & $0.61(\mathrm{~ns})$ \\
\hline \multirow{5}{*}{$\begin{array}{l}\text { Cauda helix } \\
\text { (C) point }\end{array}$} & Intraoperative & 16.57 & 0.014 & 16.58 & 0.013 & 0.31 & $0.75(\mathrm{~ns})$ \\
\hline & One week PO & 16.58 & 0.007 & 16.58 & 0.007 & 0.77 & $0.44(\mathrm{~ns})$ \\
\hline & One month PO & 16.60 & 0.010 & 16.60 & 0.009 & 1.17 & $0.24(\mathrm{~ns})$ \\
\hline & 6 months PO & 16.64 & 0.007 & 16.64 & 0.007 & 0.52 & $0.59(\mathrm{~ns})$ \\
\hline & One year PO & 16.67 & 0.010 & 16.67 & 0.011 & 0.43 & $0.66(\mathrm{~ns})$ \\
\hline \multirow{5}{*}{$\begin{array}{l}\text { Lobule } \\
\text { (D) point }\end{array}$} & Intraoperative & 20.93 & 0.017 & 20.93 & 0.012 & 1.86 & $0.07(\mathrm{~ns})$ \\
\hline & One week PO & 20.95 & 0.013 & 20.95 & 0.008 & 1.19 & $0.23(\mathrm{~ns})$ \\
\hline & One month PO & 20.97 & 0.012 & 20.97 & 0.013 & 0.76 & $0.44(\mathrm{~ns})$ \\
\hline & 6 months PO & 21.02 & 0.055 & 21.01 & 0.051 & 0.38 & $0.70(\mathrm{~ns})$ \\
\hline & One year PO & 21.10 & 0.044 & 21.09 & 0.050 & 1.33 & $0.18(\mathrm{~ns})$ \\
\hline
\end{tabular}


Table (III): Outcome in studied populations

\begin{tabular}{|c|c|c|c|c|c|c|c|}
\hline & & \multicolumn{2}{|c|}{ AS } & \multicolumn{2}{|c|}{ PS } & \multirow[t]{2}{*}{ Test } & \multirow[t]{2}{*}{$\mathrm{P}$ value } \\
\hline & & $\mathrm{n}$ & $\%$ & $\mathrm{n}$ & $\%$ & & \\
\hline \multicolumn{2}{|l|}{ Hematoma } & 1 & $2.2 \%$ & 0 & $0.0 \%$ & 1.05 & $0.30(\mathrm{~ns})$ \\
\hline \multicolumn{2}{|c|}{ Tissue necrosis } & 0 & $0.0 \%$ & 0 & $0.0 \%$ & - & - \\
\hline \multicolumn{2}{|c|}{ Local infection } & 1 & $2.2 \%$ & 0 & $0.0 \%$ & 1.05 & $0.30(\mathrm{~ns})$ \\
\hline \multicolumn{2}{|c|}{ Local hypoesthesia } & 0 & $0.0 \%$ & 1 & $2.2 \%$ & 1.05 & $0.30(\mathrm{~ns})$ \\
\hline \multicolumn{2}{|c|}{ Superficial ulcerations } & 0 & $0.0 \%$ & 0 & $0.0 \%$ & - & - \\
\hline \multicolumn{2}{|c|}{ Suture extrusion } & 2 & $4.4 \%$ & 0 & $0.0 \%$ & 2.13 & $0.14(\mathrm{~ns})$ \\
\hline \multicolumn{2}{|c|}{ Suture granuloma } & 2 & $4.4 \%$ & 0 & $0.0 \%$ & 2.13 & $0.14(\mathrm{~ns})$ \\
\hline \multicolumn{2}{|c|}{ Hyprtrophic scarring } & 2 & $4.4 \%$ & 0 & $0.0 \%$ & 2.13 & $0.14(\mathrm{~ns})$ \\
\hline \multicolumn{2}{|c|}{ Residual asymmetry } & 3 & $6.7 \%$ & 1 & $2.2 \%$ & 1.13 & $0.28(\mathrm{~ns})$ \\
\hline \multicolumn{2}{|c|}{ Total complications } & 5 & $11.1 \%$ & 1 & $2.2 \%$ & 3.04 & $0.08(\mathrm{~ns})$ \\
\hline \multirow[t]{2}{*}{ Satisfaction } & Satisfied & 39 & $86.7 \%$ & 46 & $97.9 \%$ & 4.11 & $0.043^{*}$ \\
\hline & Dissatisfied & 6 & $13.3 \%$ & 1 & $2.1 \%$ & & \\
\hline
\end{tabular}

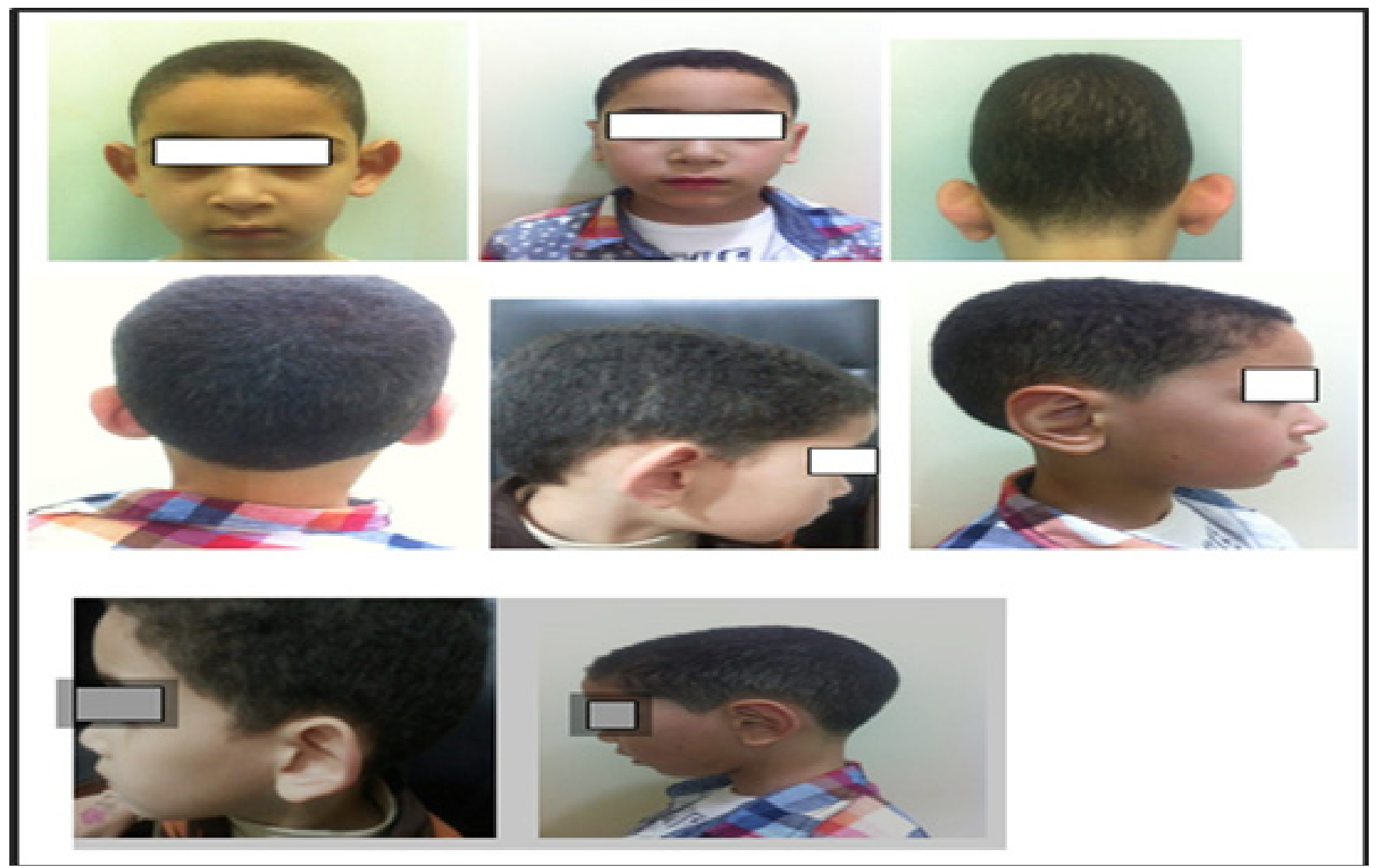

Fig. 1: Pre and posoperative photos of patient with posterior scoring technique 


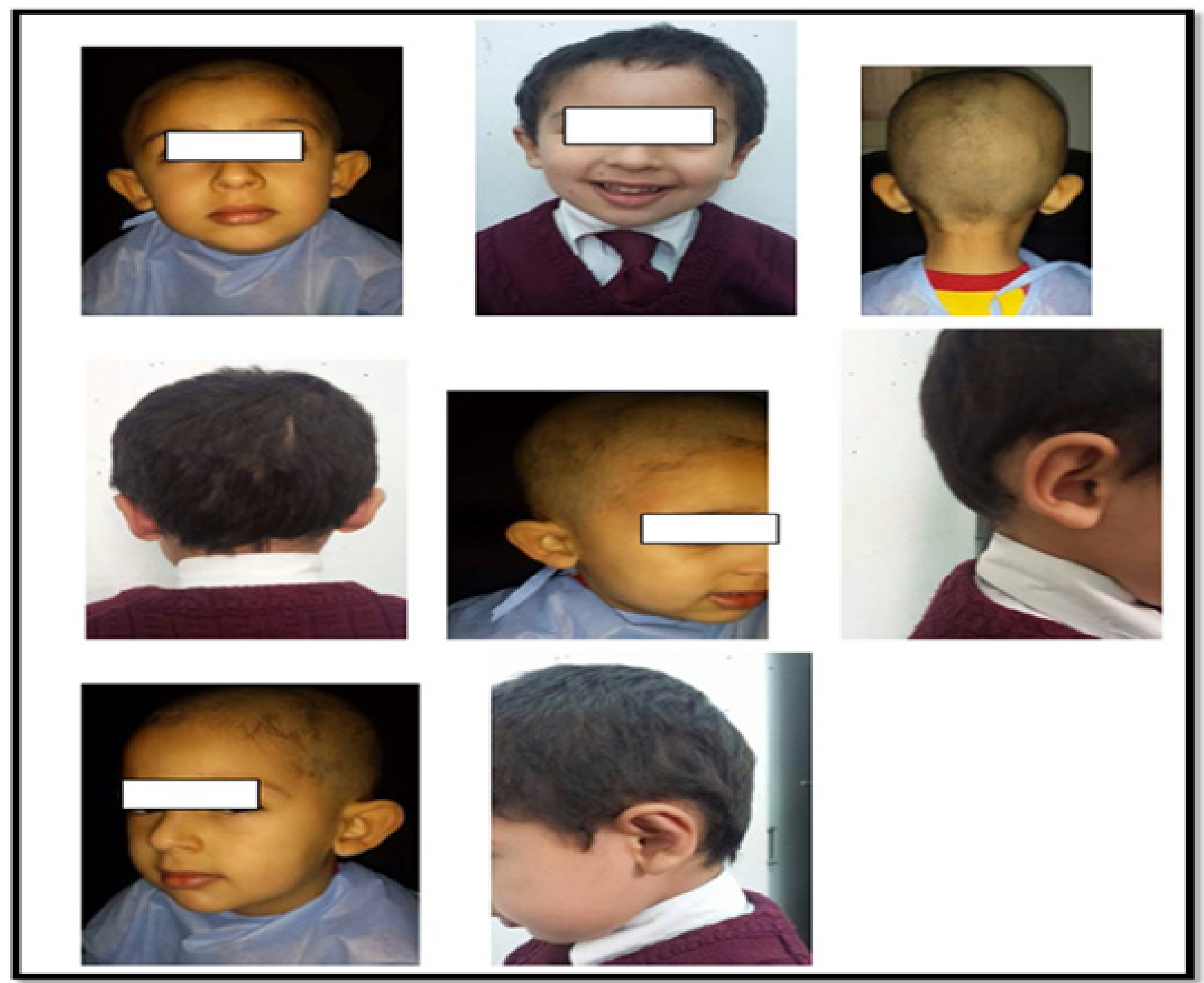

Fig. 2: Pre and posoperative photos of patient with anterior scoring technique

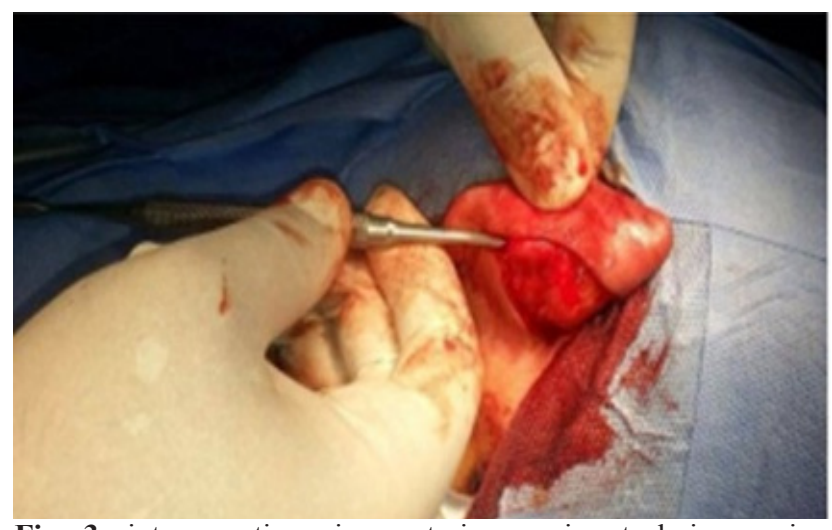

Fig. 3: intraoperative view anterior scoring technique using otorasp.

\section{DISCUSSION}

The Prominent ears should always be viewed within the context of the individual facial structure, so the choice of otoplasty technique should be individualized, aiming to create well-shaped, symmetric and natural-appearing ears, in absence of any evidence of surgical intervention ${ }^{[3,14]}$.

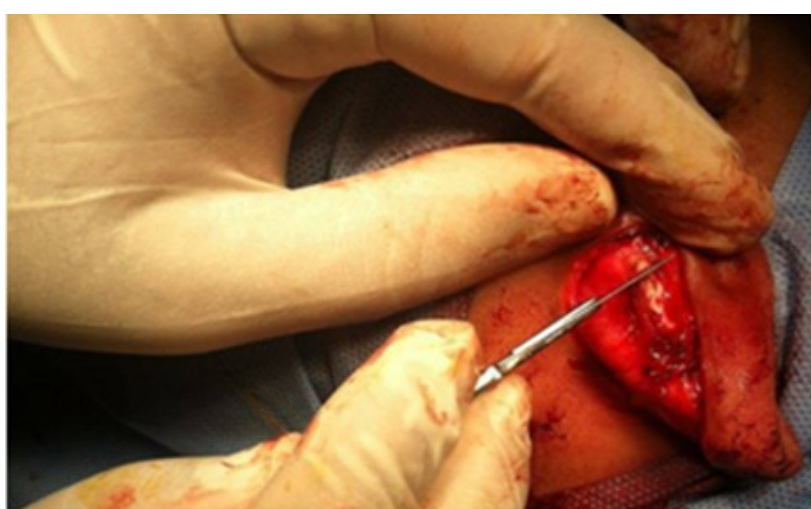

Fig. 4: intraoperative view posterior scoring technique

Different techniques were described in the literature trying to achieve these goals.

As a starting point of incision-scoring techniques, it was shown that cartilage incised on one side carry the ability to warp to the opposite side ${ }^{[15]}$. These scoring techniques were formed in the area of antihelix with or without fixation 
sutures, as described by different authors ${ }^{[11,10,16]}$. However, such scoring techniques are associated with shape irregularities and asymmetry secondary to the release of cartilage $^{[17]}$

The present study was designed to investigate the difference between anterior scoring versus posterior scoring technique in otoplasty for correction of prominent ear. Both AS and PS were comparable as regard o patient demographics and aesthetic results in general. On the other hand, posterior scoring was associated with low complications rate $(2.2 \%)$ when compared to AS $(11.1 \%)$. However, the difference was statistically non-significant. Finally, the patient satisfaction rate was significantly increased in posterior scoring group when compared to anterior scoring group ( 97.9 vs $86.7 \%$ respectively). No patient readmitted for development of recurrence or corrective secondary operation.

The idea about different scoring methods is attributed to the biomechanical properties of cartilage; as scoring is usually needed in thick or stiff auricular cartilage (above the age of 6 years) to achieve sufficient weakening of the cartilage and shaping of the antihelix.

Cartilage usually warps away from an injured surface due to the so called "internal self-locked stress system". These interlocked stresses is present in intact cartilage as a result of the growth pattern and is released by a perichondrial incision ${ }^{[18]}$.

It was reported that, anterior scoring is not sufficient for a long-lasting results in thick cartilages and had to be supported with non-absorbable sutures ${ }^{[19]}$. Similarly, Spira ${ }^{[20]}$ reported that, he used Mustarde's technique. However, He proposed using Stenstorm's closed anterior scoring technique because he found that cartilage suturing alone was insufficient for correction of prominent ear especially in adults.

The anterior scoring with posterior rolling technique was reported to give very good results with few postoperative complications $^{[21]}$. On the other hand, Hassanpour et al. ${ }^{[22]}$ used the posterior scoring approach and reported that results were 'very good' in 36 ears (80\%) and 'good' in seven ears $(15 \%)$. The rest of the ears were satisfactory (5\%). of the 25 patients, 22 patients were 'extremely satisfied', while three were 'satisfied' with the cosmetic appearance. No patient developed a recurrence or required a corrective secondary operation. These results are comparable to those of the present work. It had been reported that, posterior approach had yielded a risk of suture extrusion in $0 \%$ to $10 \%{ }^{[23,24]}$. In addition, it had been reported that, the posterior scoring approach provides precision, excellent symmetry and quality results with a short recovery time ${ }^{[25]}$.

\section{CONCLUSION}

Posterior scoring results in a high satisfaction rate with low morbidity. It was shown to be safe (low complication rate), simple and reliable intervention. Thus, we advocate posterior scoring during correction of prominent ears deformity.

\section{CONFLICT OF INTEREST}

There are no conflicts of interest.

\section{REFERENCES}

1. Dhillon RS, East CA. Ear, nose and throat, 2nd edn Churchill Livingstone- Elsevier, Edinburgh, 2006; pp 24-5.

2. Kompatscher $\mathrm{P}$, Schuler $\mathrm{CH}$, Clemens $\mathrm{S}$, et al. The cartilage-sparing versus the cartilage-cutting technique: a retrospective quality control comparison of the Francesconi and Converse otoplasties. Aesth Plast Surg 2003; 27: 446 - 53.

3. Kelley P, Hollier L, Stal S. Otoplasty: evaluation, technique, and review. J Craniofac Surg 2003; 14: $643-53$

4. Sivrioglu N, Irkoren S, Aksoy B et al. Anterior Scoring Technique for the Correction of Prominent Ears: Results in 30 Patients. Mod Plast Surg, 2012; 2: 39

5. Bogetti P, Boltri M, Spagnoli G, et al. Otoplasty for prominent ears with combined techniques. Eur J Plast Surg 2003; 26: 144-8

6. Adamson PA, Strecker HD. Otoplasty techniques. Facial Plast Surg 1995; 11: 284 - 99.

7. Preuss S, Eriksson E. Prominent ears. In: Van der Kolk E, ed. Plastic surgery: indicators, Operations and Outcomes. St Louis: Mosby; 2000: 1057 - 65.

8. Nachlas NE. Otoplasty. In: Papel ID, ed. Facial Plastic and Reconstructive Surgery. 2nd ed. New York, Stuttgart: Thieme; 2002: 309-21.

9. Janis JE, Rohrich RJ, Gutowski KA. Otoplasty. Plast Reconstr Surg 2005; 115: 60e - 72e.

10. Stenstrom SJ. A natural technique for correction of congenitally prominent ears. Plast Reconstr Surg 1963; 32: 509.

11. Chongchet V. A method for antihelix reconstruction. Br J Plast Surg 1963;16: 268

12. Hafezi F, Naghibzadeh B, Nouhi AH et al. Anterior Scoring Approach for Prominent Ear Anomaly: A Modi_ed Chongchet Technique. Arch Iran Med. 2013; 16(4): $225-8$ 
13. Campbell AC. Otoplasty. Facial Plast Surg 2005; 21: $310-16$

14. Vuyk HD. Cartilage-sparing otoplasty: a review with longterm results. J Laringol Otol 1997; 3: 424-30.

15. Gibson T, Davis W. The distortion of autogenous cartilage grafts: its cause and prevention. Br J Plast Surg 1958; 10: 257.

16. Crikelair GF. Another solution for the problem of the prominent ear. Ann Surg 1964; 160: 314-24.

17. Fioramonti P, Serratore F, Tarallo M et al. Otoplasty for prominent ears deformity. Eur Rev Med Pharmacol Sci 2014; 18: 3156-65.

18. Fry HJ. Interlocked stresses in human nasal septal cartilage. Br J Plast Surg 1966; 19: 276-8.

19. Corchado C. A surgical technique for the correction of all types of prominent ears? Plast Reconstr Surg 2000; 106: 948
20. Spira M. Otoplasty: what I do now: a 30 year perspective. Plast reconstr Surg 1999; 104: 834.

21. Peker F, Celikoz B. Otoplasty. Anterior scoring and posterior rolling technique in adults. Aesth Plast Surg 2002; 26: 267- 73 .

22. Hassanpour SE, Moosavizadeh SM. Posterior scoring of the scapha as a refinement in aesthetic otoplasty. J Plast Reconstr Aesthet Surg. 2010 Jan;63(1):78-86

23. de la Torre J, Tenenhaus M, Douglas BK, et al. A simplified technique of otoplasty: the temporary kaye suture. Ann Plast Surg 1998; 41:94-6.

24. Gosain AK, Recinos RF. Otoplasty in children less than four years of age: surgical technique. J Craniofac Surg 2002; 13:505-9.

25. Nolst Trenite' GJ. Otoplasty: a modified anterior scoring technique. Facial Plast Surg 2004; 20:277-85. 